\title{
EDUCAÇÃO PARA A PAZ: INTEGRANDO A EXTENSÃO E A PESQUISA NO ENSINO SUPERIOR
}

\author{
Nei Alberto Salles Filho ${ }^{1}$ \\ ORCID: 0000-0003-4231-2988 \\ Virgínia Ostroski SALles ${ }^{2}$ \\ ORCID: 0000-0003-4231-2988
}

\begin{abstract}
Resumo: Este artigo resume a trajetória de construção do Núcleo de Educação para a Paz da Universidade Estadual de Ponta Grossa, Paraná (NEP/UEPG). O objetivo central é perceber a processo que efetivou o NEP/UEPG ao longo dos últimos quinze anos, bem como sua consolidação como projeto de extensão institucional, com repercussão regional na formação continua de profissionais da educação, saúde e assistência social. O NEP/UEPG atua nas questões da prevenção de violências e qualificação das convivências humanas a partir dos campos integrados dos valores humanos, direitos humanos, mediação de conflitos, ecoformação e atividades vivenciais. Como metodologia será realizado um relato de experiência, devidamente fundamentado em pesquisa bibliográfica, com as referências centrais que embasam a própria concepção do NEP/UEPG. Como resultados e conclusões são apresentadas algumas características das ações desenvolvidas pelo projeto, tanto em sua dimensão na extensão universitária, como nas relações com a pesquisa e a produção do conhecimento, além do papel relevante na discussão das políticas públicas relacionadas à Cultura de Paz.
\end{abstract}

Palavras-chave: Educação. Direitos Humanos. Cultura de Paz. Educação para a Paz.

1 Professor da Universidade Estadual de Ponta Grossa, Paraná. Mestre e Doutor em Educação. Docente no Programa de Pós-Graduação em Ciências Sociais Aplicadas. Coordenador do Núcleo de Educação para a Paz - NEP/UEPG. E-mail: (nsalles@uepg.br). Página oficial do NEP/UEPG: (www.uepg.br/nep).

2 Mestre e Doutoranda (bolsista CAPES) em Ensino de Ciência e Tecnologia na Universidade Tecnológica Federal do Paraná (UTFPR- Campus Ponta Grossa). Participante voluntária no Núcleo de Educação para a Paz - NEP/UEPG. E-mail: (virginia.utfpr@gmail.com). 


\title{
EDUCATION FOR PEACE: INTEGRATING EXTENSION AND RESEARCH IN HIGHER EDUCATION
}

\begin{abstract}
This article summarizes the construction path of the Núcleo de Educação para a Paz (Peace Education Center) from the Universidade Estadual de Ponta Grossa, Paraná (NEP/ UEPG). The main objective is to understand the process that has made the NEP/UEPG over the last fifteen years, as well as its consolidation as an institutional extension project, with regional repercussions in the continuing education of professionals in education, health and social assistance. The NEP / UEPG acts on the issues of violence prevention and qualification of human coexistence from the integrated fields of human values, human rights, conflict mediation, ecotraining and experiential activities. As methodology will be an experience report, duly based on bibliographic research, with the central references that support the very conception of NEP UEPG. As results and conclusions are presented some characteristics of the actions developed by the project, both in its dimension in the university extension, as in the relations with the research and the production of the knowledge, besides the relevant paper in the discussion of the public politics related to the Culture of Peace.
\end{abstract}

Keywords: Education. Human rights. Culture of Peace. Education for Peace.

\section{EDUCACIÓN PARA LA PAZ: INTEGRACIÓN DE LA EXTENSIÓN E INVESTIGACIÓN EN LA EDUCACIÓN SUPERIOR}

Resumen: El artículo resume las formas de construir el Centro de Educación para la Paz de la Universidade Estudual de Ponta Grossa, Paraná (NEP/UEPG). El objetivo principal es comprender el proceso que ha llevado a cabo la NEP/UEPG durante los últimos quince años, así como su consolidación como un Proyecto de Extensión Institucional, con repercusiones regionales en la educación continua de los profesionales de la educación, la salud y la asistencia social, en los temas de prevención de la violencia y calificación de la convivencia humana. Para este propósito, se utilizará un informe de experiencia, debidamente basado teóricamente en la investigación bibliográfica, con las referencias centrales que apoyan la propia concepción NEP/ UEPG. A medida que se presentan los resultados y las conclusiones, se presentan las principales acciones llevadas a cabo por el proyecto, tanto en su dimensión de extensión como en sus relaciones con la docencia y la investigación, además del papel relevante en la discusión de políticas públicas relacionadas con la Cultura de la Paz.

Palabras claves: Extensión. Educación. Derechos humanos. Cultura de Paz. Educación para la Paz.

Submetido em: 01/09/2019.

Aceito em: 07/10/2019. 


\section{INTRODUÇÃO}

Os pensamentos e as reflexões sobre o tema "paz" sempre caminharam na tentativa de encontrar um consenso relacionado a situações positivas e conectadas a uma ideia de bem, como oposição ao mal. Este consenso, tende a conceber questões ligadas aos valores pretensamente universais como respeito, solidariedade, generosidade, amor, harmonia etc. Dessa forma pensamos, por muitos séculos, que este conjunto de valores do "bem" automaticamente levaria à uma paz universal como finalidade da humanidade.

Por outro lado, o que vimos e vemos como traço definidor da humanidade, em diferentes tempos, espaços e momentos históricos é um quadro mais complexo, muitas vezes o oposto aos valores atribuídos à paz. Assim, a violência é o caminho que conduz uma infinidade de práticas e relações entre pessoas, grupos, países e até mesmo na dimensão do planeta. Violências de múltiplas formas, da agressão física direta à miséria e a pobreza, passando por guerras e pela falta de água e alimentos para milhões de seres humanos, além da destruição do próprio meio ambiente. O alerta já havia sido dado por Oliveira (1995) quando disse que o século XX colocou a paz como problemática central da humanidade, seja pelo holocausto ou pela bomba atômica, como uma necessidade de reflexão ética sobre o futuro da civilização.

A partir do breve contexto, algumas questões saltam aos olhos: afinal, a paz é um conceito ou apenas uma ideia abstrata? A paz existe ou é apenas utopia? Como fica a perspectiva de paz diante de situações tão violentas e cruéis vividas pela humanidade? A paz seria destinada apenas para as religiões? Mas, e a intolerância religiosa que também gera tanta violência? Ainda, a paz nasceria no coração das boas pessoas? Isso é possível? Afinal, a paz seria apenas um ideal, sem sentido para a realidade humana? Estaríamos destinados, portanto, a uma cultura de violência, das fatalidades, das guerras entre países, pessoas, das violências guardadas em nossas vidas como seres humanos, sociais e históricos?

O conjunto destas provocações marcou um pequeno grupo de professores universitários, mais precisamente atuantes no Curso de Educação Física da Universidade Estadual de Ponta Grossa, no início dos anos 2000, especialmente ao observar a violência crescente nas escolas, através das ações realizadas no Estágio Supervisionado escolar, quando os alunos do referido curso estavam nas escolas para realizar práticas pedagógicas, sob a supervisão conjunta destes docentes. 


\section{DOS PROBLEMAS REAIS À PESQUISA E CONSTRUÇÃO DO CONHECIMENTO}

Do contexto inicial, pensando alternativas adequadas para refletir melhor todas estas questões, foi organizado o projeto de extensão denominado "Núcleo de Estudos e Práticas Pedagógicas da Educação Física" (NEPPEF/UEPG), desenvolvido entre os anos de 2001 e 2003, com o objetivo de pensar a Educação Física nas relações humanas nas escolas, particularmente nas questões sobre indisciplina, violências e convivências, com o foco de contribuir com possibilidades das práticas pedagógicas para esta disciplina escolar. Assim, conteúdos como relaxamento corporal, jogos com ênfase na expressão corporal e na cooperação eram estudados e aplicados em escolas públicas da educação básica, avaliando seu potencial pedagógico, particularmente observando as convivências entre os alunos.

Nesse aspecto, a principal contribuição aos estudos se deu pela perspectiva de Paulo Freire, de onde percebemos que a prática da Educação Física seria muito importante, mas que as questões das violências e convivências escolares eram muito mais amplas e complexas. Já nos primeiros passos, Freire nos inspirou a partir de um fragmento de seu discurso quando recebeu o prêmio Educação para a Paz da UNESCO (1986), alertando para a dimensão ampla do entendimento da paz:

De anônimas gentes, sofridas gentes, exploradas gentes aprendi, sobretudo que a Paz é fundamental, indispensável, mas que a Paz implica lutar por ela. A Paz se cria, se constrói na e pela superação de realidades sociais perversas. A Paz se cria, se constrói na construção incessante da justiça social. Por isso, não creio em nenhum esforço chamado de educação para a Paz que, em lugar de desvelar o mundo das injustiças o torna opaco e tenda a miopizar as suas vítimas (FREIRE apud GADOTTI, 1996, p. 52).

Considerando esta visão crítica, compreendemos para entender as violências era necessário compreender a paz, e que a paz não é uma condição natural, muito menos a violência, uma vez que ambas são construídas histórica e socialmente. Sendo assim, pareceu aceitável explicitar um corpo de conhecimento que pense a paz, na educação e na formação de professores, como um conjunto de saberes, práticas e experiências passíveis de reflexão, análise e sistematização. Portanto, Paulo Freire expressa uma luta pela paz na realidade de nosso país, especialmente em relação às desigualdades sociais e injustiças.

Neste caminho, avaliando especialmente as experiências e o aprendizado, com reflexões mais profundas sobre o ser humano e a sociedade, o NEPPEF/UEPG passa a ter atenção com as questões macro e micro referentes às violências e convivências 
escolares, além da Educação Física. Durante os estudos e práticas do referido projeto, encontraram-se muitas experiências relacionadas à educação em valores, educação em direitos humanos e a educação para a paz nas escolas, uma vez que se utilizavam de várias atividades esportivas, corporais e culturais em suas ações. Uma parte destas questões foi incorporada ao NEPPEF/UEPG, outra parte continuou como provocação para ampliar os conhecimentos.

Com estes desafios, finalizamos o ciclo do projeto de extensão NEPPEF/UEPG e propusemos um projeto de pesquisa institucional, que vigorou entre os anos de 2004 e 2006, intitulado "Configurando elementos teóricos e práticos da Educação para a Paz". Este projeto buscou, ao longo de dois anos, pesquisas e práticas pedagógicas referentes à prevenção de violências, metodologia de valores humanos, direitos humanos, mediação de conflitos e ações que poderiam ser classificadas como pertencentes ao espectro de uma perspectiva de Cultura de Paz com um viés potencialmente pedagógico, ou seja, a Educação para a Paz.

Com o aprofundamento deste projeto de pesquisa, algumas questões ficaram claras: em países europeus, desde o final dos anos de 1960, a Educação para a Paz já era discutida e pesquisada; na América Latina estas discussões já apareciam nos anos de 1990; no Brasil questões sobre a Cultura de Paz ganham força no início dos anos 2000. Também percebemos que as contribuições chegavam ao Brasil de forma desordenada, fragmentada, através de leituras limitadas de documentos da Organização das Nações Unidas (ONU) e Organização das Nações Unidas para a Educação, a Ciência e a Cultura (UNESCO). Ao mesmo tempo e, como ponto importante da pesquisa, houve acesso aos fundamentos da Educação para a Paz, estudados e desenvolvidos ao longo de mais de quatro décadas especialmente na Europa.

No decorrer dos estudos referentes ao projeto de pesquisa, três estudiosos foram fundamentais para a construção sobre a Educação para a Paz como campo de estudos a ser sistematizado também no Brasil. Primeiro, o norueguês Johan Galtung, que trata das diferentes formas de violência. Conforme Galtung (1994) existem quatro distinções básicas de violência e que podem contribuir didaticamente para entender a Educação para a Paz: a) violência clássica, que vai da guerra ao homicídio; b) a pobreza e a privação material; c) a repressão e a privação/violação dos direitos humanos, d) a alienação e a negação das necessidades superiores, entendidas como a possibilidade de desenvolvimento cultural, educacional, espiritual entre outros. Entender que a violência tem inúmeras formas de manifestação, que vão desde as violências diretas até as estruturais, foi um aspecto central para a pesquisa.

O segundo autor foi o espanhol Xesús Jares, com a discussão da Educação para a Paz como a resolução criativa e não-violenta dos conflitos. Aprofundando 
no pensamento de Jares (2002) alguns argumentos foram fundamentais e acabaram incorporados até hoje no trabalho que é realizado, especialmente sobre noção positiva de paz, compreendida como um conjunto de valores ou habilidades para superar a maior parte das diferenças e divergências entre pessoas e grupos. Além disso, a cooperação como valor, pode encontrar este estado de paz - como formas de igualdade, justiça e reciprocidade. Quando estes valores ganham dimensão dos países, pode-se dizer que são valores relacionados ao desenvolvimento humano e ao avanço civilizatório. Assim, a justiça social, as políticas públicas sérias, os níveis elevados de moralidade e ética, a promoção da cidadania e dos direitos humanos são aspectos fundamentais deste avanço na humanidade e civilização. Nesta relação direta entre os direitos humanos com a paz, Jares (2002) diz:

[...] o conceito de direitos humanos refere-se primeiramente ao sentido de dignidade, da dignidade humana, que é, mais do que qualquer formulação jurídica ou política, uma condição ou qualidade moral, inerente a todo ser humano sem nenhum tipo de limitações, sejam econômicas, físicas, culturais, raciais, sexuais, etc (JARES, 2002, p. 128).

Ao relacionar os direitos humanos à dignidade como valor humano, Jares (2002) aproxima estas questões. O entendimento "clássico" dos direitos humanos, ligado às questões jurídicas, historicamente acabou esquecendo os indivíduos em si, com seus sofrimentos e dificuldades. Até recentemente, em termos históricos, a justiça só favorecia quem detinha maior poder (financeiro, político etc.). Só recentemente, especialmente nos países em desenvolvimento, a dignidade como igualdade de direitos vem ganhando espaço. Nesse sentido podemos dizer que a paz é o contrário da violação de direitos. Isso equivale a dizer que não podemos encontrar a dignidade humana onde imperem a dominação de raças, sexos, exércitos ou ditaduras.

A terceira fonte, nos estudos da paz, foi Gloria Perez Serrano, que contribuiu decisivamente para a concepção crítica sobre a paz. Para Serrano (2002) a Educação para a Paz é nutrida pela abertura à diversidade, aos direitos humanos e à democracia, pois permite acolher diferentes dinâmicas culturais e sociais. Por isso, fortalecemos nosso projeto de pesquisa com as reflexões de Serrano (2002) que comenta:

Consideramos que se deve fomentar nas escolas e nos centros universitários a educação para a paz, pois esse valor forma uma trama com outros valores, ligados entre si que se exigem uns aos outros. Assim, a educação para a paz exige formar o espírito crítico, a capacidade de dialogar, a veracidade, a coerência de meios-fins e a justiça. Ela não é compatível com o individualismo, a falta de solidariedade, a competitividade, a discriminação, etc (SERRANO, 2002, p. 83). 
Ao propor que a Educação para a Paz habite o ensino superior, Serrano (2002) faz uma colocação que está no conjunto de nossa reflexão. Mesmo os jovens e adultos precisam rever questões sobre as violências, os conflitos, a paz e as convivências humanas. É absurda a forma com que muitas pessoas ou famílias relacionam-se em pleno século XXI, como os casos de violência contra as mulheres e ao aumento das denúncias de abuso sexual contra crianças.

Além disso, a deterioração do tecido social e familiar, tem a ver com a cultura do individualismo, da comparação, do egoísmo, da inveja e da falta de acreditar no potencial positivo das relações humanas. A partir deste conjunto de reflexões, que também impactou os docentes e discentes em suas conviç̧ões pessoais acerca das questões sobre paz e violência, podemos afirmar que o projeto de pesquisa se constituiu no divisor de águas de nosso entendimento sobre o potencial educacional da Educação para a Paz.

Guiados por estas questões, mas sem perder o olhar sobre a Educação Física, foi desenvolvido, concomitante ao projeto de pesquisa o "Núcleo de Estudos da Ludicidade e Jogos Cooperativos" (LUDCO/UEPG) como outro projeto de extensão institucional (2005-2007), baseado fundamentalmente em dinâmicas e vivências em grupo, com fundamentos na ludicidade e na ideia de cooperação como elemento privilegiado para qualificar as relações humanas e construir uma Cultura de Paz, considerando os valores da tolerância, respeito e solidariedade. Ao trabalho do LUDCO/UEPG foram inseridas questões relativas aos valores humanos, com práticas sendo desenvolvidas em vários grupos, desde a educação infantil, passando pelo ensino fundamental e médio, na educação de jovens e adultos e no ensino superior. Este projeto envolveu muitos alunos do Curso de Educação Física em ações nos diferentes espaços.

Do processo integrado do projeto de pesquisa, buscando conhecimento sobre a Cultura de Paz e, do projeto de extensão tratando as relações humanas baseadas na ludicidade, foram definidos novos direcionamentos ao trabalho, considerando dois aspectos: 1) a necessidade de discussão conceitual para contribuir na formação de professores; 2) a importância de prever atividades vivenciais devidamente conectadas aos conceitos, evitando senso comum. A Educação para a Paz abria essa possibilidade de releituras sobre violências e convivências escolares, não apenas focadas em dados da violência e em casos extremos do cotidiano escolar, mas sim, nos processos de construção das relações positivas, através de práticas pedagógicas. Além disso, com o trabalho do LUDCO/UEPG reforçamos a importância das práticas vivenciais humanizadoras como ponto fundamental das relações interpessoais, prevenção de violência e mediação de conflitos. Este ciclo ensinou muito ao grupo de professores e alunos. 
Ao final desta etapa, uma parte do grupo inicial de professores, que estiveram juntos desde a criação do NEPPEF/UEPG (2001-2003), passando pelo Projeto de Pesquisa "Configurando elementos teóricos e práticos da Educação para a Paz" (2004-2006) e pela experiência do LUDCO/UEPG (2005-2007), seguiram caminhos distintos, alguns mais relacionados aos aspectos da Educação Física e outros procurando ampliar na discussão e a construção específica sobre a Educação para a Paz no contexto educacional.

\section{A EDUCAÇÃO PARA A PAZ E O NEP/UEPG}

O pensamento da Educação para a Paz, embasado em processos de mediação de conflitos, em discussão crítica sobre os direitos humanos e a busca por uma educação pautada em valores/princípios não violentos (tanto individuais, como sociais, estruturais e ambientais) foram aspectos provocativos que levaram a perceber a importância da produção de conhecimentos e experiências nestes campos. Nesse percurso, a opção foi em socializar as informações da pesquisa sobre a Educação para a Paz de forma direta com os professores da educação básica, devido à demanda crescente sobre as violências escolares. Lembramos aqui que, desde o início de nossa caminhada com o NEPPEF/UEPG, no ano de 2001, já havíamos acumulado estudos e experiências, mas ao mesmo tempo as violências escolares ficavam cada vez mais intensas nas escolas brasileiras.

A decisão foi que, a melhor forma de compartilhar os saberes sobre os movimentos de Cultura de Paz e Educação para a Paz, seria com a criação do "Núcleo de Estudos e Formação de Professores em Educação para a Paz" (NEP/UEPG), no formato de projeto de extensão, com o objetivo de atuar na formação continuada de professores em metodologias de prevenção de violência, valores humanos, direitos humanos e mediação de conflitos escolares. A aprovação do projeto ocorreu em 2008 e permanece em funcionamento até os dias atuais. No ano de 2016 o projeto passa a ser registrado apenas como "Núcleo de Educação para a Paz - NEP/UEPG”, por uma questão de funcionalidade e também pela forma como o projeto ficou conhecido ao longo dos anos. Nesta fase, seguimos uma premissa importante levantada por Tuvilla Rayo (2004, p. 110):

A Educação para a Paz requer uma verdadeira aprendizagem social que permita não apenas a aquisição dos conhecimentos essenciais sobre a sociedade e a melhor forma de participar dela (aprender a viver consigo mesmo e os demais), mas também exige a aquisição daqueles conhecimentos e estratégias de transformação, de conduzir-se por novos valores, socialmente construídos, que respondam com criatividade às novas problemáticas estabelecidas no presente e no futuro. 
Assim, a primeira fase do NEP/UEPG (2008-2010) foi marcada por encontros com professores da educação básica, fundamentalmente da educação pública municipal e estadual, falando sobre o movimento da Cultura de Paz, sobre valores humanos, direitos humanos e da importância das práticas escolares preventivas e baseadas em convivências positivas e melhoria de clima escolar. O objetivo era discutir sobre o enfoque mais amplo da Cultura de Paz e a sua respectiva tradução em práticas pedagógicas, a Educação para a Paz, foco do projeto.

Nos anos que se seguiram, a partir de 2011 em diante, a metodologia do NEP/ UEPG foi construída em duas vertentes: a primeira na organização de grupo de estudos, com número reduzido de professores, aprofundando nas questões teórica da Educação para a Paz; a segunda, na formação de professores por meio de cursos, palestras e oficinas, com menor discussão teórica, mas com densidade conceitual adequada e voltada para a intervenção em projetos escolares cotidianos.

Ressaltamos que, do grupo de estudos formado por professores da educação básica e do ensino superior, foram consideradas as demandas das escolas, ajudando a tornar os cursos e oficinas mais próximos e direcionados às diferentes realidades educacionais. Além disso, do grupo de estudos, houveram muitos protagonistas de ações da Educação para a Paz nas redes de ensino dos municípios da região de Ponta Grossa. Ainda destaca-se a publicação de artigos e participação em eventos regionais e nacionais apresentando questões relativas ao projeto.

Um fato relevante se dá a partir do ano de 2012, quando profissionais de outras áreas, além de professores da educação básica, passam a procurar o NEP/ UEPG. Foram educadores sociais, assistentes sociais e psicólogos buscando reflexões sobre os estudos da paz. Isso se deu pelo fortalecimento do Sistema Único de Assistência Social (SUAS) no Brasil e a perspectiva multidisciplinar adotada especialmente pelos Centros de Referência de Assistência Social (CRAS) que atuam com famílias (mulheres, idosos e adolescentes). Além disso, muitas instituições com o trabalho socioeducativo passaram a participar das palestras e cursos.

Recentemente, a partir de 2013, a Ordem dos Advogados do Brasil (OAB), o Juizado de Violência contra a Mulher e a Defensoria Pública do Estado do Paraná, no município de Ponta Grossa, mantiveram interfaces com o NEP/UEPG, em ações relacionadas à Educação em Direitos Humanos e nas práticas restaurativas, movimentos que tem como base os processos de pacificação social. A partir desta ampliação, o olhar das experiências e estudos desenvolvidos pelo NEP/UEPG foi alargado, não apenas para os sistemas de ensino formais, mas também para projetos socioeducativos e outras intervenções com famílias, mulheres, idosos e grupos de jovens. Este crescimento teve como pano de fundo a percepção crítica sobre os 
direitos humanos no Brasil no início do século XXI, apoiada em dimensões ligadas aos organismos internacionais. A esse respeito, afirma LUCAS (2013):

\begin{abstract}
Apesar dos problemas de efetividade material, a defesa dos direitos humanos tem se consolidado e envolvido, cada vez mais, os organismos internacionais e as organizações não governamentais, bem como preocupado um número sempre mais significativo de cidadãos individualmente considerados. De fato, a Organização das Nações Unidas transformou os ideais da paz e de proteção dos direitos humanos numa referência importante da agenda internacional (LUCAS, 2013, p. 23).
\end{abstract}

Outro fato que sustenta o argumento de Lucas, foi a parceria desenvolvida junto ao Instituto Mundo Melhor, uma entidade do terceiro setor de Ponta Grossa, que resultou de muitas ações positivas em cidades da região, além da organização de um material didático referente à Educação para a Paz (cartilha pedagógica e livros com relatos de experiência). Considerando as questões tratadas até aqui, podemos dizer que a Educação para a Paz foi pensada e concretizada em diversos municípios ao longo destes mais de dez anos. Evidentemente, isso pode ser somado às outras regiões, cidades e estados, além de muitas Instituições de Ensino Superior, Secretarias de Educação, Assistência Social, Saúde entre outras, preocupadas com a prevenção de violências e qualidade das convivências entre alunos, profissionais, famílias e comunidades.

O que nos fortaleceu, neste caminho, foi o relato de Jares (2007) dizendo que na Espanha, a Educação para a Paz chegou e foi aceita nas Universidades após trinta anos de práticas nas escolas. Em nosso caso, caminhamos com estas descobertas de forma conjunta, desenvolvendo práticas escolares e comunitárias com a temática da paz, com desdobramentos na educação superior, particularmente na extensão e na pesquisa. Isso mostra que, além do ensino de qualidade, as universidades públicas desempenham um papel social relevante para a sociedade, em diversos campos. Em nosso caso, os campos das ciências humanas e sociais pode ter uma perspectiva aplicada à sociedade, especialmente aos grupos atendidos por instituições públicas.

Mesmo com toda esta caminhada, ainda é necessário reconhecer que, mesmo existindo um caminho teórico da Educação para a Paz construído há quase cinco décadas na Europa e que tomou contornos metodológicos na Espanha nos últimos trinta anos, ainda não está sedimentado o campo da Educação para a Paz na educação brasileira. São inúmeras e excelentes práticas pedagógicas que precisam, depois destes anos, ganhar robustez nos registros e na pesquisa, para gerar evidências coerentes. A esse respeito, Guimarães (2005, p. 325) alerta: 
[...] a educação para a paz não é messiânica ou redentora, uma espécie de via fácil para a paz, ou um método infalível que, bastando aplicá-lo, transformaria a face da violência. A educação para a paz não é garantia de resultado certo, nem há uma relação de causa-efeito entre educação para a paz e diminuição da violência: a paz e a educação para a paz são destituídas de toda onipotência e ornadas de todas as vulnerabilidades.

Portanto, é fundamental reconhecer que, neste processo da Educação para a Paz, existe a possibilidade de reflexão profunda sobre o fenômeno da violência e das múltiplas alternativas de utilização das convivências humanas no sentido da qualidade das relações. A Educação para a Paz não se pretende científica no sentido fechado, mas sim, humanizadora e socialmente comprometida com uma metodologia que entenda e atue positivamente nas questões dos valores humanos, direitos humanos, conflitos e por fim, criadora de um ambiente qualitativo entre nas instituições. Alertamos que qualquer "receita milagrosa para a paz", sem considerar sua relação com a violência, os conflitos, os direitos humanos e a sustentabilidade, não podem resistir ao cotidiano das escolas, uma vez que não consideram a própria realidade.

Nas experiências acompanhadas pelo NEP/UEPG percebemos o dilema acima, onde bons projetos e boas práticas são encaminhados com perspectivas promissoras, porém, dependem dos passos seguintes, como a adequação às propostas pedagógicas das escolas ou ainda, o acolhimento dos projetos pelos sistemas das políticas públicas municipais, estaduais e nacional. Assim, evidenciamos que a carência quanto ao conhecimento teórico e metodológico da Educação para a Paz, precisa ser equacionada. Por isso, mantemos o duplo aspecto do NEP/ UEPG, de um lado informar e disseminar conhecimentos sobre os estudos da paz e, de outro, trazer estes dados para a pesquisa, gerando práticas pedagógicas cada vez mais qualificadas e embasadas em experiências sólidas.

Como exemplo, vale relatar que ao longo dos anos foram certificados pelo NEP/UEPG aproximadamente mil profissionais, a maioria do campo educacional, mas, também das áreas de assistência social e saúde, que efetivaram estudos e reflexões sobre o tema além de desenvolver projetos-piloto sobre Educação para a Paz em seus respectivos campos de atuação profissional. Isso se deu tanto em Ponta Grossa como em aproximadamente dez municípios da região de abrangência da UEPG. Nesse sentido, com os profissionais desenvolvendo projetos concretos como forma de avaliação dos cursos realizados, multiplicamos os estímulos sobre os temas das violências, dos conflitos e da paz. 


\section{DA EXTENSÃO À PESQUISA E A REPERCUSSÃO NAS POLÍTICAS EDUCACIONAIS: REALINHANDO OS NOVOS DESAFIOS}

Mesmo com tantos caminhos trilhados, na difusão do conhecimento sobre Cultura de Paz e Educação para a Paz através da extensão universitária, ao longo dos anos de atuação do NEP/UEP, percebemos que novos passos e desafios foram sendo incorporados. Certamente os profissionais que passaram pelos cursos e oficinas (que variam entre oito e quarenta horas), obtiveram noções básicas sobre os campos de conhecimento centrais onde o projeto atua: valores humanos, direitos humanos, mediação de conflitos, ecoformação e vivências. São profissionais de diversas áreas, pedagogos, educadores sociais, assistentes sociais, psicólogos, advogados além de estudantes universitários destas mesmas áreas.

Cabe relembrar que, como já foi dito, nos cursos de maior duração são solicitadas, como forma de avaliação, ações práticas nas diferentes atuações profissionais, objetivando tornar o conhecimento um elemento vivo nas práticas sociais. Assim, são os profissionais que sentem no cotidiano os limites e possibilidades de inserção da Educação para a Paz em suas diversas realidades. Isso fica mais claro quando consideramos a discussão de Vinyamata (2005):

Em conflitologia, os métodos de intervenção não são justificados pelos fins que se perseguem; pelo contrário, os fins perseguidos são o resultado dos meios empregados. Portanto, os métodos são sempre não-violentos, pacíficos, mais indutivos que diretivos, polifacéticos, respeitosos para com a dignidade humana, dispostos a incidir nas causas, a transformar sua perversidade. O fim perseguido não é outro senão o de facilitar de maneira prática, a justiça social, a dignidade e a liberdade de pessoas e de sociedades, as necessidades humanas essenciais, a harmonia e a capacidade de convivência, a saúde de pessoas e sociedades (VINYAMATA, 2005, p. 15)

Esta reflexão, relacionada ao campo da mediação dos conflitos mostra que o processo de Educação para a Paz precisa considerar os meios, a metodologia de atuação em face das diferentes realidades. Importa criar uma Cultura de Paz e de direitos humanos baseada no entendimento de dignidade humana e na qualidade de conviver com os demais, a partir dos problemas individuais e coletivos. Logo, a Educação para a Paz, como campo que tem potencial para agregar e integrar diferentes discussões, requer um maior cuidado em seu tratamento no ensino superior, para dar um retorno mais efetivo para a sociedade. 
Assim, como resultados dessa reflexão-ação sobre a práticas pedagógica e sociais, a demanda sobre o estudo e a pesquisa da Educação para a Paz, com seus campos relacionados, ganhou novos contornos. Nesta ampliação, foi criado o Grupo de Pesquisa em Cultura de Paz, Direitos Humanos e Sustentabilidade (UEPG), em 2017, que passou a integrar profissionais das diferentes áreas interessados em aprofundar a pesquisa e a produção científica. Este grupo possui a característica de receber profissionais de diferentes cidades do estado do Paraná, dispostos a pensar a um enfoque multidisciplinar, marcadamente relacionado aos estudos do pensamento complexo. Nesse cenário, concordamos Edgar Morin (2012) que:

A educação para a paz não indica que a paz é melhor que a guerra. Todos sabem disto. Mas, o problema é que a paixão e a histeria política a poluíram. Como humanidade, estamos possuídos pelos nacionalismos e fundamentalismos. A educação para a paz não significa ensinar que a paz é uma coisa muito boa, mas significa ensinar a compreensão humana. Isso é uma coisa fundamental no caminho da paz (MORIN, 2012, p. 38).

Com isso, é importante ressaltar que a Educação para a Paz, aliada aos campos dos direitos humanos e da sustentabilidade, ocupa um papel reflexivo central no século XXI. É fato que a vida está em esgotamento, desde os seres humanos até os animais e o próprio planeta. Portanto, abordar o presente e o futuro da humanidade requer um pensamento complexo que reúna diferentes e diversos olhares de vários campos do conhecimento. É sobre isso que o Grupo de Pesquisa em Cultura de Paz, Direitos Humanos e Sustentabilidade concentra seus estudos.

Além disso, a repercussão do NEP/UEPG também faz interface com o Grupo de Pesquisa Direitos Humanos, Cidadania e Políticas Públicas do Programa de Pós-Graduação em Ciências Sociais Aplicadas (UEPG), criado em 2018. Aqui, estudantes do mestrado e doutorado encontram possibilidade de aprofundar pesquisas relacionadas à Cultura de Paz e Educação para a Paz nas relações diretas com os direitos humanos, particularmente a partir dos estudos críticos da área e com perspectivas relacionadas às Epistemologias do Sul, pela discussão de Boaventura Sousa Santos e Bruno Sena Marinho (2019) entre outros. Para os autores:

[...] os direitos humanos hoje vigentes, como linguagem hegemónica de dignidade humana, só poderão ressignificar-se a partir de respostas a perguntas simples: Por que há tanto sofrimento humano injusto que não é considerado uma violação dos direitos humanos? Que outras linguagens de dignidade humana existem no mundo? Essas outras linguagens são ou não compatíveis com a linguagem dos direitos humanos? Estas questões, como se imagina, só poderão ser respondidas de modo satisfatório se conseguirmos imaginar uma radical transformação daquilo que hoje reconhecemos como direitos humanos (SANTOS; MARINHO, 2019, p. 13-14). 
Como vemos, todos os caminhos do NEP/UEPG, desde os projetos que o antecederam, foram permeados por indagações sobre o ser humano e a sociedade, especialmente em relação à desigualdade e injustiça. Produzir reflexões, conhecimento e práticas sociais no Brasil requer estas múltiplas dimensões. Por isso a integração entre extensão e pesquisa, foi e é fundamental. Porém, como a preocupação central sempre foi com a sociedade, o foco do NEP/UEPG também se conecta em aspectos das políticas públicas dos anos recentes e que trazem sentido, significado e motivação para o trabalho. Neste cenário, um primeiro marco ocorre quando da explicitação, na Lei n. 13.005/2014 que aprovou o Plano Nacional de Educação (2014-2024), de dois aspectos relacionados à Educação para a Paz; o primeiro, sobre a importância do combate às várias formas de violência $\mathrm{e}$, a segunda, a necessidade de inclusão da Cultura de Paz nos estabelecimentos de ensino.

A partir disso, cabe evidenciar que a Comissão de Educação da Câmara dos Deputados promoveu uma audiência pública voltada à discussão da Cultura de Paz, em outubro de 2015, de onde foram extraídos elementos para a criação de uma Comissão Parlamentar de Cultura de Paz. Esta comissão, nos anos de 2017 e 2018, também promoveu audiências públicas que fomentaram a discussão da importância da Educação para a Paz se tornar parte mais incisiva da legislação educacional do país. Nesse sentido, a decisão da Comissão foi de sedimentar o entendimento da Cultura de Paz no contexto da Lei n. 9394/1996, a Lei de Diretrizes e Bases da Educação Nacional (LDB). Isso se concretizou com a Lei 13.663 de 14 de maio de 2018, que insere na LDB as seguintes questões: "IX - promover medidas de conscientização, de prevenção e de combate a todos os tipos de violência, especialmente a intimidação sistemática (bullying), no âmbito das escolas; $\mathrm{X}$ - estabelecer ações destinadas a promover a cultura de paz nas escolas”.

Consideramos que a alteração promovida na LDB é mais uma parte significativa na construção da Educação para a Paz na educação brasileira. Trata-se de um momento onde todas as experiências realizadas pelas escolas do país podem receber maior atenção, visibilidade e que, finalmente, a discussão sobre a prevenção das violências, a qualificação das convivências e Cultura de Paz sejam tratadas pedagogicamente. Os novos desafios estão postos, fazer com que a convivências escolares sejam objeto de estudo mais palpável, que valores como respeito, solidariedade e tolerância sejam efetivamente entendidos através de práticas pedagógicas. Particularmente, em nosso momento atual, a educação precisa considerar a tolerância como um dos valores fundamentais para a Cultura de Paz, num tempo de agressões gratuitas e desprovidas de humanidade. Nisso, evidenciamos o que Droit (2017) diz: 
[...] a tolerância que nos interessa é a que diz respeito à nossa vida em sociedade, com todos os outros, com nossas diferenças e divergências, é uma questão de relação entre nós. Ela não reside em um organismo, ela existe entre as pessoas, na maneira de se falarem, de se olharem, de se julgarem, no modo como se comportam umas em relação às outras (DROIT, 2017, p. 21)

A tolerância só é possível "entre as pessoas", ela não pode existir numa relação individual, portanto é um valor essencialmente relacional. É disso que a Educação para a Paz é nutrida, das relações humanas a partir de conjuntos de valores, que se desdobram em direitos humanos, que por sua vez trazem os conflitos pela pluralidade e, onde podem-se construir pontes através da mediação. Ao mesmo tempo, tudo isso ocorre num templo a céu aberto, que é a natureza e o meio ambiente, passível de sofrer violência e construir paz pela dimensão da sustentabilidade. Desta complexidade, unida por elos da vida, que se ocupa a Educação para a Paz.

\section{CONSIDERAÇÕES FINAIS}

Consideramos que retomar a história e a constituição dos estudos da paz, observando a trajetória desenvolvida na Universidade Estadual de Ponta Grossa, é fundamental para entender a evolução das ideias concretizadas em ações de extensão universitária e pesquisa acadêmica nos últimos anos. O NEP/UEPG nasceu alguns anos antes de ser oficializado, no momento em que algumas questões preocupavam professores de um campo de conhecimento (Educação Física) para além das questões específicas da área, mas em pensar mais profundamente as bases da violência na sociedade e nas escolas.

Ao longo dos anos, sempre aliando a extensão à pesquisa, foi possível conhecer outros campos, como os direitos humanos, a mediação de conflitos, a discussões sobre sustentabilidade, que compõe a complexidade de uma Cultura de Paz. Entendendo que uma Cultura de Paz só é possível com uma Educação para a Paz, seguimos no caminho de entender suas discussões específicas, em melhorar as perspectivas metodológicas, integrar aspectos cognitivos, afetivos e sociais, na tentativa de contribuir com o cotidiano das instituições, especialmente as escolas, oferecendo formação continuada, material didático e reflexões teóricas. Acreditamos que isso confere identidade e densidade ao trabalho da Educação para a Paz, como contribuição ao cenário dos estudos da paz no país, com o cuidado em sempre observar às realidades escolares com suas alegrias, tensões e construções. Como nos lembra Gadotti (2008): 
A escola não é só um lugar para estudar, mas para se encontrar, conversar, confrontar-se com o outro, discutir, fazer política. Deve gerar insatisfação com o já dito, o já sabido, o já estabelecido. Só é harmoniosa a escola autoritária. A escola não é só um espaço físico. É, acima de tudo, um modo de ser, de ver. Ela se define pelas relações sociais que desenvolve. E se ela quiser sobreviver no século 21, precisa buscar nela o que é específico dela numa sociedade de redes e de movimentos que é a sociedade atual (GADOTTI, 2008, p. 92-93).

A sociedade de redes e de movimentos do século XXI só pode ser construída a partir de diálogos, conflitos, mediação, respeito, amorosidade, solidariedade e tolerância, voltados ao desenvolvimento, democracia e dignidade/direitos humanos, numa expressão, com Cultura de Paz. Assim, a escola deste século será, certamente, a escola da Educação para a Paz, com múltiplos nomes, com várias alternativas, mas com a humanização crescente diante da desumanização persistente. Se os seres humanos foram tão hábeis em construir violências, agora é o momento de sermos criativos para construir a paz. É sobre isso que o NEP/UEPG tem feito sua trajetória!

\section{REFERÊNCIAS}

DROIT, Roger-Pol. Tolerância: o que é? Por que é importante? : É possível nos dias de hoje? : Como educar para a tolerância? São Paulo, SP: Contexto, 2017.

GADOTTI, Moacir (et.al.) Paulo Freire: uma biobibliografia. São Paulo: Cortez: Instituto Paulo Freire, Brasília: Unesco, 1996.

. Reinventando Paulo Freire na escola do século 21. In: TORRES, Carlos Alberto (et. al.) Reinventando Paulo Freire no século 21. São Paulo: Instituto Paulo Freire, 2008. 135 p.

GALTUNG. Johan. Direitos Humanos: uma nova perspectiva. Lisboa, Portugal: Instituto Jean Piaget, 1994. 252 p.

GUIMARÃES, Marcelo Rezende. Educação para a paz: sentidos e dilemas. Caxias do Sul, RS: Educs, 2005.

JARES, Xesus. Educação para a paz: sua teoria e sua prática. 2. ed. rev. Tradução de Fátima Murad, Porto Alegre: Artmed, 2002. 271 p. 
. Educar para a paz em tempos difíceis. Tradução de Elizabete de Moraes Santana. São Paulo: Palas Athena, 2007. 193 p.

LUCAS, Doglas Cesar. Direitos humanos e interculturalidade: um diálogo entre a igualdade e a diferença. Ijuí: Unijuí, 2013. 320 p.

MORIN, Edgar. Os sete saberes necessários à educação do presente. In: MORAES, Maria Cândida; ALMEIDA, Maria da Conceição. Os sete saberes necessários à educação do presente: por uma educação transformadora. Rio de Janeiro: Wak, 2012.

OLIVEIRA, Manfredo. Ética e práxis histórica. São Paulo: Ática, 1995. 190 p.

SANTOS, Boaventura de Sousa; MARTINS, Bruno Sena. Introdução: o pluriverso dos direitos humanos. In: SANTOS, Boaventura de Sousa; MARTINS, Bruno Sena (orgs.) O pluriverso dos direitos humanos: a diversidade das lutas pela igualdade. Belo Horizonte: Autêntica, 2019. 538 p.

SERRANO, Gloria Pérez. Educação em valores: como educar para a democracia. Tradução de Fátima Murad. Porto Alegre: Artmed, 2002. 262 p.

TUVILLA RAYO, José. Educação em direitos humanos: rumo a uma perspectiva global. Tradução de Jussara Haubert Rodrigues. Porto Alegre: Artmed, 2004. 247 p.

VINYAMATA, Eduard. Compreender o conflito e agir educativamente. In:VINYAMATA, Eduard (org.). Aprender a partir do conflito: conflitologia e educação. Tradução de Ernani Rosa. Porto Alegre, Artmed, 2005. 